\title{
Exploration and practice of blended teaching of cell biology experiments during the COVID-19 epidemic
}

\author{
Peng Li ${ }^{1 \#}$, Meiting Li ${ }^{1 \#}$, Lili Tian ${ }^{1 \#}$, Jie Xiao ${ }^{1}$, Guilin Xiang ${ }^{1}$, Xizhi Ding ${ }^{1}, X_{i a n g}$ Qin $^{2}$, Rong Jiang ${ }^{1}$, \\ Juan Liao ${ }^{3}$ \\ ${ }^{1}$ Department of Anesthesiology, Sichuan Provincial People's Hospital, University of Electronic Science and Technology of China, Chengdu, China; \\ ${ }^{2}$ School of Life Science and Technology, University of Electronic Science and Technology of China, Chengdu, China; ${ }^{3}$ Department of Stomatology, \\ Sichuan Provincial People's Hospital, University of Electronic Science and Technology of China, Chengdu, China \\ Contributions: (I) Conception and design: P Li, X Qin, J Liao; (II) Administrative support: L Tian, R Jiang; (III) Provision of study materials or \\ patients: M Li, J Xiao; (IV) Collection and assembly of data: G Xiang, X Ding; (V) Data analysis and interpretation: P Li, J Liao; (VI) Manuscript \\ writing: All authors; (VII) Final approval of manuscript: All authors. \\ \#These authors contributed equally to this work. \\ Correspondence to: Juan Liao. Department of Stomatology, Sichuan Provincial People's Hospital, University of Electronic Science and Technology of \\ China, Chengdu, China. Email: 109497731@qq.com; Rong Jiang. Department of Anesthesiology, Sichuan Provincial People’s Hospital, University \\ of Electronic Science and Technology of China, Chengdu, China. Email: anthea_365@163.com; Xiang Qin. School of Life Science and Technology, \\ University of Electronic Science and Technology of China, Chengdu, China. Email: qinxiang@uestc.edu.cn.
}

\begin{abstract}
Since 2019, new coronavirus pneumonia has been widespread worldwide and has had a direct impact on human life. Meanwhile, it also has a huge impact on teaching in universities and hospitals, especially in experimental courses. Cell biology is not only an important part of biology but also one of the most dynamic frontier branches of modern life science, which is also a science based on experiments. It is necessary to promote the online and offline teaching during this special period. To explore and evaluate the blended teaching modes during the COVID-19 epidemic, we changed the previous single teaching mode of "teaching + experiment" and published courseware and learning requirements online before class, this kind of mode takes "theory + virtual demonstration experiment" in class as the main body and the reviewing and thinking after class as the summary. We also carried out offline practice on a small scale when the epidemic allowed and actively explored the comprehensive online and offline teaching modes, in and out of class. Through the hybrid teaching, the percentage distribution of students in high and moderate scores ranges were greatly increased, the blended teaching mode also greatly improves students' subjective initiative and highlights the development of students' personalized thinking and scientific research ability. The practice of this model not only ensures the health of teachers and students during the epidemic but also provides a new teaching exploration model and thinking for the development of experimental courses during the epidemic.
\end{abstract}

Keywords: Epidemic; online teaching; cell biology; offline practice; blended teaching

Submitted Dec 17, 2021. Accepted for publication Jan 27, 2022.

doi: $10.21037 /$ atm-22-55

View this article at: https://dx.doi.org/10.21037/atm-22-55

\section{The challenges of traditional experimental courses and online teaching during the COVID-19 epidemic}

The outbreak of new coronavirus pneumonia at the end of 2019 made people's daily lives and social interaction press the pause button (1). However, with the vigorous development of internet plus, the development trend of information technology used in classroom teaching has provided the possibility for online teaching (2). Baker of Sedarville University in the United States put forward the concept of flipped classrooms, which also promoted 
the application of computer technology in experimental research $(3,4)$. Jowsey et al. also emphasized the importance of blended learning, and revealed that active engagement was the key for student success (5). Blended teaching is a kind of "online" + "offline" teaching that combines the advantages of online and traditional teaching. Through the organic combination of the two teaching organization forms, learners' learning can be led from shallow to deep. Cell biology, as a branch of basic medicine, needs face-toface communication between teachers and students $(6,7)$. However, when face-to-face communication becomes difficult during an epidemic, ensuring the quality of courses, especially the smooth development of experimental courses, poses new challenges to teachers. The traditional experimental course design is "teaching + experiment". The online course needs to break the original teaching mold and explore a new model. In the process of practice, we also find that there are some prominent problems in traditional experimental teaching, such as insufficient students' indepth thinking of the experimental course and insufficient expansion and innovation of the experimental content. Meanwhile, there are also significant problems in the mode of simple simulated offline teaching to "online teaching + virtual experiment". For example, students have no intuitive feelings about new technologies and methods. In particular, during the epidemic period, it was more difficult to stimulate students' thirst for knowledge of the practical and improve thinking ability if they only watched several experimental method videos on the screen. The combination of network technology and teaching has become an important subject of reform, which is of great significance in improving the experimental teaching mode. In addition, with the development of biological technology, new experimental methods of cell biology are also emerging $(8,9)$.

Taking advantage of this reality, we reorganized teaching resources and processes, moved offline classes to online classes by changing the traditional "teaching + experiment" mode, presented and consolidated knowledge by means of preclass previews, in-class learning and after class review, and encouraged students to accept the application-oriented direction by improving assessment and evaluation methods. By changing the old teaching contents and methods, which are relatively single, lack coherence, and do not allow students to have systematic learning and design experiments, we make full use of the multichannel advantages of information in the new era during the epidemic period. Through online teaching, online virtual experiment demonstration, student discussion and Q\&A, students' independent design experiments and offline practice, subjective initiative, students' thirst for knowledge and investment in the development of cell biology experiments are all evoked, which also maximizes the teaching effect and quality in this special period.

\section{Characteristics and contents of cell biology experiments}

Teaching contents and systems are the core of the curriculum and play an important role in talent training (10). The courses of cell biology experiments at our university are divided into several levels, basic and professional. Experimental teaching is an important part of undergraduate talent training, which directly affects students' innovation ability, practical ability and problem analysis and thinking ability. For the basic quality education course, it is very important to mention the interest of undergraduates in cell biology. Meanwhile, in the experimental design, we also followed the principle of hierarchical progression and worked to enable students to master increasingly comprehensive basic knowledge, methods and technologies of cell biology.

Specifically, cell biology (basic class) mainly includes four modules. The first module is the introduction of basic cell biology instruments, which take up $25 \%$ of the total time. This section introduces the history and current practice of the development of the pipette and enzymelabeled instrument and combines the current hot issues, such as new coronavirus pneumonia diagnosis, as the basic and irreplaceable role of the basic pipette and enzymelabeled instrument. A conventional microscope will also be introduced to give students a basic understanding of the basic instruments of cell biology and lay a foundation for follow-up studies. The second part is the cell culture and cytoskeleton staining experiment, accounting for $25 \%$ of the total class hours. Students can enter their cell level studies from basic instruments and master the methods of cell culture, including the basic operation and aseptic concept of cell fluid exchange, passage, cryopreservation and resuscitation, as well as the basic experimental methods such as cell counting. In terms of cytoskeleton staining, we will teach students to intuitively see a more microscopic world from the subcellular level through the method of fluorescence microscopy, stimulate students' interest in learning, and provide familiarity with the analysis methods of different types of microscopes for different experimental results. The third part is the extraction and identification 
of plasmid DNA, accounting for $25 \%$ of the total class hours. Students will further explore the mechanism of genes affecting cell life functions at the molecular level. This part is close to clinical practice, which helps the students learn the methods of extracting DNA and identification analysis, as well as the interpretation and analysis of identification reports. The first three modules introduce basic knowledge from simple to deep understanding. The fourth module guides the students through independent experimental design. Although it only accounts for $25 \%$ of the total class hours, students need to spend more second class time to improve the experimental design to complete this part. It is also the key to this hybrid teaching. On the basis of previous knowledge, we also guide students to referenceinduced self-education (RISE). The self-learning teaching mode widens the information channel and actively explores knowledge through reading of the latest literature. Students' knowledge in class is limited; only by actively searching for information after class can they cultivate their ability to analyze and solve problems and promote the collaborative innovation of course content (11).

We also guided students to actively search for knowledge through internet platforms, such as FDA websites, patent websites and Chinese woodworm forums. At the same time, we also introduce literature search methods to help students effectively obtain recent research reports, such as those in NCBI, PubMed, CNKI, Google, etc. In this module, four students are divided into a group. Everyone participates in the design of the experiment and is responsible for the practice of different stages of the follow-up experiment. The experimental task and goal given by teachers is to design experiments to explore scientific problems according to the knowledge learned in the previous order, combined with their own reading of literature and today's social hot spots. This part not only requires students to consolidate their previous knowledge but also requires students to have the ability to think logically to design a complete experiment. Each team member needs to conduct 2-3 online exchanges and discussions on the background, content and expected results of the designed experiment, with teachers participating in the whole process and taking the initiative to ask questions. The division of labor and cooperation and resource sharing of each team member also exercises the team cooperation spirit of students. Projects independently designed by students can be carried out offline in the laboratory when the epidemic situation allows and the design operability is also strong. More indepth projects can be further carried out by graduate students or later scientific research work. The design of experiments integrates students' fragmented knowledge, improves students' subjective initiative, and exercises students' independent thinking and autonomous learning abilities. Because most of the virtual experiments cannot be carried out online, such experiments can only be carried out offline at a selected time, which requires personalized and customized services in the experimental course. At the same time, each group needs to display the PPT in front of the whole class. The students will put forward opinions to improve the experimental design to make the follow-up experimentation more efficient and smoother. The fourth module examines the comprehensive ability of self-level detection and design experiments. It is complementary to and interconnected with the previous three modules.

\section{Exploration of blended teaching}

\section{Preparation and practice of online teaching in class}

Different from the previous practice of giving students courseware after class, we preview the courseware for online teaching courses. Students can think according to their basic knowledge and facilitate subsequent communications. The foundation of students is actually uneven. Giving the learning content to students in advance will not only help some students with weak foundations master basic experimental techniques and methods but also help students with good foundations put forward some in-depth questions to improve the experiment. For example, in the use of optical and fluorescence microscopy, some students do not know about optical microscopy. Such students need to learn background knowledge about the optical path of the microscope. Some students have a deep understanding of optical microscopy, but they do not know the principles of fluorescence microscopy. This student needs to focus on the similarities and differences between fluorescence and optical microscopy. Students who have a good understanding of both optical and fluorescence microscopy need to explore how to make good use of this kind of instrument to carry out research. This kind of differentiated preparation is mainly completed before class. Each student needs to give feedback on relevant courseware, which will let teachers know the situation of students to carry out follow-up teaching work. This process is not only a review of previous knowledge but can also efficiently use limited experimental class time, making "theory + practice" more practical. Before class, teachers send courseware and videos to students. Students 
need to provide feedback on their preparations so that teachers can understand students' situations and difficulties in real time. The core purpose of blended teaching is to let students have more time for self-learning in the second classroom. Although teaching of theory is mainly online before class, it is not limited to courseware, but also includes the combination of background knowledge. It also requires students to conduct in-depth learning and discussion through network resources to form their own knowledge or doubts, which is convenient for subsequent analysis and the experimental design of the fourth module. If the epidemic situation permits, we will also provide multiple tasks, such as key and difficult Q\&A and discussion offline, to jointly ensure the depth and breadth of the teaching of theory.

\section{Create a theory and practice teaching mode in class}

Cell biology experiments are a practical course, and teaching of experiments is the main method for students to acquire ability. The cultivation of students' practical ability in blended teaching is the key factor for students to have a sense of gain in this course. For special reasons, this course is first displayed online as a virtual experiment, which also includes the explanation and display of the experimental operation. Online teaching can be different from traditional teaching, and some high-level demonstration experiments can be carried out to make students feel that high technology surrounds them. For the main modules, the experiments are 1:1:1 of the phenomenal level, cell level and molecular level. In this modular teaching, the modules for students are to understand the basic instrument operation, the cell operation and the molecular level operations. Each part of the theory is accompanied by experiments to enable students to understand the knowledge points of the online course. The fourth module promotes the reform of heuristic and participatory teaching methods. The teacher introduces the history and background of the experiment so that the students can actively understand the necessity of the experiment, spontaneously design the experiment, and design the purpose-oriented experiment by themselves in the form of group discussion. The teaching time needs to increase so that students can fully understand and design the experiment. As a practical means, experiments are also indispensable. Teachers will assist students in preparing experiments according to the experimental design and summarize and analyze successes and failures in groups to make the experimental class an exploratory course to give full play to students' subjective initiative.
After the traditional introduction to the basic operation, class hours were arranged to encourage students to carry out spontaneous design experiments. For example, in the process of cytoskeleton staining, students learned theoretically that phalloidin can stain the cytoskeleton for intuitive observation, but students showed great interest in the dyeing process. For example, some groups investigated whether different actin staining temperatures will affect the final effect of actin (actin itself exists in the cell membrane and cytoplasmic region), some groups investigated whether the concentration of actin will affect the final effect, and some groups investigated whether the treatment time of actin will affect the final skeleton distribution characteristics. Such questions seem to be basic, but the textbook does not answer relevant questions. Through the discussion of relevant questions, students understand the possible impact and significance of different factors on the results and propose ideas for subsequent students to design experiments. In the writing of the experimental report, we also encourage students to analyze the possible effects of different factors on the experiment and their causes on the premise of writing the background, methods and results. Teachers will carefully read the students' experimental reports and analyze the students' input to provide better guidance for the independent design of the next experiment.

\section{Independent design experiment}

Experimental classes are traditionally carried out in a stepby-step manner, with prepared reagents/drugs and detailed process explanations. This programmed experiment obtains predictable results, and students lack curiosity about the experiment $(12,13)$. How to encourage students to participate in experimental design is very important for the cultivation of their ability to analyze and solve problems. Meanwhile, students should also learn how to analyze failed experiments and how to make experiments successful, which will greatly enhance students' participation in experimental courses. In the process of students' independent experimental design, we also require students to master the necessity of designing such cell biology experiments, master the basic essentials of self-designed experiments and analyze the possible reasons for the failure of the experimental design. By consulting online resources, we can explore the subject and discover future research topics. Team work also shows that different students can carry out appropriate work assignments according to their own strengths, reflecting the characteristics of individualized education and differentiated 


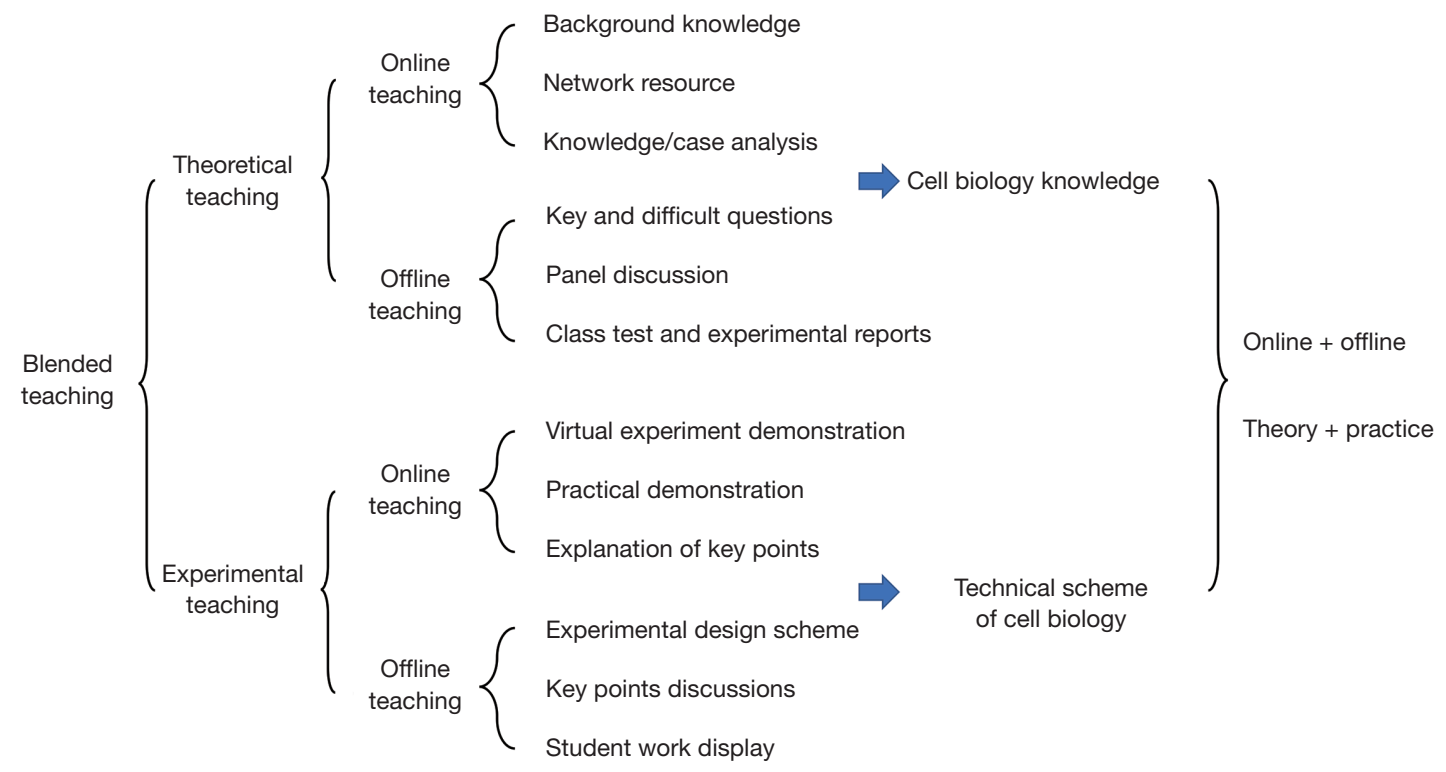

Figure 1 Implementation means of blended teaching mode.

education. For example, after studying previous work, a group proposed studying the effect of different green tea concentrations on tumor cell proliferation. The group integrated the use of early equipment and instruments and the basic operation of cell culture and created plans according to the interest points and social hot spots of the group. Different students in the group have their own strengths. Some are good at collecting background information, some are good at experimental operation, and some have advantages in PPT sorting and expression. Although it is very important for each student to grow independently, they can also learn from their strengths in team cooperation, maximize the value of team members, and give team members a good sense of participation. We propose that we can only complete the experimental design, group discussion and other work in our class hours, and offline development needs to be carried out in the second classroom or even in future scientific research activities. After learning the cell biology experiment course, some students actively applied for provincial and national life science competitions, trained in more targeted project design, data query, problem analysis and problem solving in the project, and had the opportunity to win good awards or form scientific research papers to lay the foundation for future scientific research work and improve basic knowledge, this new teaching concept also strengthens students' experimental skills and encourages their innovative in practice. The basic implementation means of the blended teaching mode are shown in Figure 1.

\section{Evaluation of blended teaching}

We actively promote the reform of students' academic evaluation, assessment content and assessment methods, strengthen the diversification of learning process evaluation and students' achievement constituent elements, and promote the reform of nonstandard answer examination. The blended teaching experimental design is displayed in groups in the form of PPT, and the experimental operation and report are used as assessment indicators. Special attention was given to the experimental design and result analysis, and the experimental results were diluted. The classroom/after class platform, such as rain class, were used for group member discussions. Before each group submits the plan, we encourage each group to communicate their experimental plan and learn from each other. Teachers scientifically evaluate the advantages and disadvantages of students' spontaneous experimental design and propose feasible suggestions. The innovation of the spontaneous design experiment and the modification of the experimental design are also included in the final assessment. Compared with the traditional teaching mode, the assessment method is $30 \%$ for the classroom performance (including classroom test) and $70 \%$ for the experimental report. The new hybrid teaching method breaks the traditional scoring mode, and the classroom performance is improved to $70 \%$ (including 


\begin{tabular}{|c|c|c|}
\hline Assessment items & Contents & Scores \\
\hline Classroom test & $\begin{array}{c}\text { Self-study feedback before class } \\
\text { Online learning completion } \\
\text { Questions after class }\end{array}$ & 30 points \\
\hline Experimental design & $\begin{array}{c}\text { Reports exchange } \\
\text { Experimental design } \\
\text { Experimental results and analysis } \\
\text { Contributions on experimental design } \\
\text { Panel discussions }\end{array}$ & $\begin{array}{l}\text { Teacher's evaluation } 20 \text { points } \\
\text { Students' mutual evaluation } 20 \text { points }\end{array}$ \\
\hline Experimental reports & $\begin{array}{l}\text { Introduction to background } \\
\text { Logic of experimental process } \\
\text { Experimental results and discussions } \\
\text { Experimental summary and expansion }\end{array}$ & 30 points \\
\hline
\end{tabular}

Figure 2 Composition of assessment of cell biology experiment under blended teaching mode.

$30 \%$ for the course test and $40 \%$ for the experimental design). Thirty percent of the score includes classroom performance, including the comprehensive score of the preclass preview, learning and thinking in class. The reason why $40 \%$ of the score is put in the experimental design is that this is not only a summary of the previous knowledge but also a preliminary exploration of future learning ability. In the same group, teachers can score reasonably according to the specific contents in the experimental design (the score of the experimental design part accounts for 50\%) and students' mutual evaluation score (the score of the experimental design part accounts for $50 \%$ ) in the $40 \%$ of scores, and the other $30 \%$ is the score of the traditional experimental report (Figure 2).

Although the proportion of the experimental report in the total score has decreased significantly, we have higher requirements for the experimental report. For the experimental report, we not only required students to clearly write the experimental purpose, methods and results but also analyze the experimental results and describe the assumption of future experimental expansion. This model avoids the mistaken assumption of writing experimental reports randomly. We assess the percentage distribution of students in different scores ranges. Practice shows that compared with the traditional teaching mode (taking 2019-2020 fall semester as an example), students' scores of more than 90 account for $0 \%$, scores of $86-90$ account for $26 \%$, scores of $81-85$ account for $26 \%$, scores of $76-80$ account for $11 \%$, scores of $70-75$ account for $11 \%$, and scores of less than 70 account for $26 \%$. Most of them are concentrated in 81-90 range and are evenly distributed. After the blended teaching mode (taking the 2020-2021 fall semester as an example), $5 \%$ of the students have more than 90 points, $75 \%$ have $86-90$ points, $5 \%$ have $81-85$ points, $0 \%$ have $70-80$ points and $15 \%$ have less than 70 points. Compared with the traditional teaching mode, the ability of high-scoring students can be seen. Most students evenly distributed in the 81-90 score range are among the 86-90 scores after the blended teaching mode, and the number of students in 70-80 score range was reduced under the new mode, as shown in Figure 3. This shows that the blended teaching mode greatly improves students' subjective initiative, which can not only make excellent students better but also make ordinary students better. Although the evaluation mode of blended teaching greatly limits the proportion of experimental reports in the total score, it highlights the development of students' personalized thinking and scientific research ability, which is conducive to providing valuable experience for them to engage in subsequent scientific research work. Through the improvement, we clearly defined the means of blended teaching in the experimental classes and concluded the positive results of the hybrid teaching.

\section{Prospect of experimental course teaching mode under the environment of epidemic normalization}

Only when the curriculum is alive can the talent training system be alive (14). Through continuous optimization, the experimental course during the epidemic period has carried out a series of explorations in teaching content, teaching means and methods, classroom assessment and so on, which provides experience for the blended 


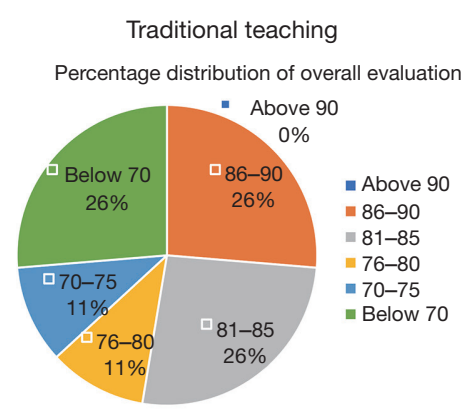

Distribution chart of general evaluation results 2019-2020 fall semester

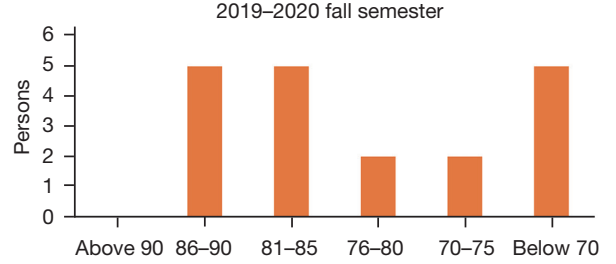

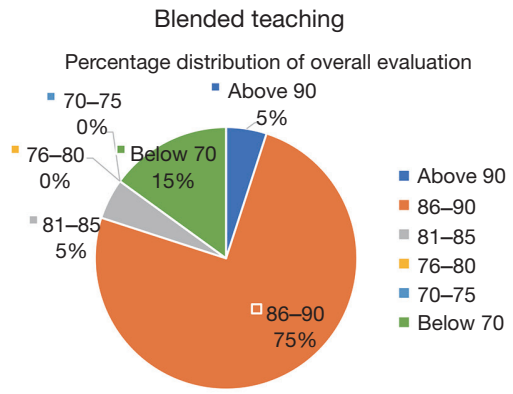

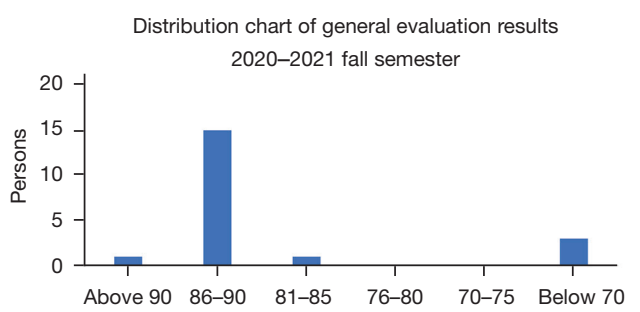

Figure 3 Comparison of the proportion of students in each fraction of cell biology experiment scores in undergraduate classes in the 20192020 and 2020-2021 fall semesters.

teaching of experimental courses. We also believe that the understanding of a subject through course learning is far from sufficient. We need to make full use of the time in the second classroom to better cultivate students' scientific research ability. It is also possible of the hybrid teaching mode to be applied to the other courses. In the next stage, this course will continue to deepen the beneficial results of the course and continue to promote the reform of the teaching curriculum system. In the future, a completely offline environment can also integrate favorable factors such as online resource sharing and group discussion, make full use of the time in the second classroom, promote students' learning and strengthen the teaching effect of the course.

In RISE, students also put forward new challenges to teachers. Students choose a wide range of subjects and various forms of content, which requires teachers to track the development of the industry in time and puts forward new requirements for teachers' learning ability. In the context of students' independent topic selection, teachers also need a broader knowledge reserve to effectively guide students. At the same time, the efficiency of classroom discussion can be improved, which is also a spur for teachers' lifelong learning ability and comprehensive quality. Through interactive learning, students' ability to analyze biological problems continues to rise, and their interest in biology majors is also significantly strengthened. The learning ability, oral expression ability and experimental operation ability of subsequent professional courses have played a good guiding role. The design of the experiment should be close to the foundation knowledge, which could be used to tackle frontier scientific questions. For the platform, we also call for improving development and resource sharing. At present, the platform design of virtual experiments is not mature and does not promote the sharing of resources. Teachers need targeted preparation to enable students to obtain relevant knowledge (15). The evaluation system should be applied more to abilities rather than reports, and the most important scores cannot be given only by the experimental report; otherwise, it is difficult to reflect the differences of students.

In conclusion, the results show that blended teaching can significantly improve students' enthusiasm, autonomy and the ability to think independently and cooperatively. Hybrid teaching also complements the shortcomings of traditional teaching. Students have significantly improved their grades. They speak freely in group discussion, which fully enlivens the atmosphere and makes the discussion free from the restrictions of time and space. The online demonstration experiment shortens the waiting time, and students' thinking has been moving rapidly, changing passive reception into active learning. During the COVID-19 epidemic, it is necessary to conduct the hybrid teaching method. Although online teaching can achieve some results by improving teaching contents and methods, 
offline communication is still essential. How to make full use of network resources to serve experimental teaching still needs in-depth teaching practice and exploration. On the premise of normalized epidemic prevention and control in the future, we should also combine the online and offline teaching modes, make full use of the time in the second classroom, and attract more students' interest in cell biology to cultivate more professional talent.

\section{Acknowledgments}

Funding: This work was supported by the Science and Technology Plan Project of Sichuan Province, China (2019YJS0221 and 2020YJ0452); Sichuan Provincial People's Hospital Institute Research Fund, China (2017YL18); National Natural Science Foundation of China (82170634); and the Scientific Research Project of Health Commission of Sichuan Province, China (18PJ160).

\section{Footnote}

Conflicts of Interest: All authors have completed the ICMJE uniform disclosure form (available at https://atm. amegroups.com/article/view/10.21037/atm-22-55/coif). The authors have no conflicts of interest to declare.

Ethical Statement: The authors are accountable for all aspects of the work in ensuring that questions related to the accuracy or integrity of any part of the work are appropriately investigated and resolved.

Open Access Statement: This is an Open Access article distributed in accordance with the Creative Commons Attribution-NonCommercial-NoDerivs 4.0 International License (CC BY-NC-ND 4.0), which permits the noncommercial replication and distribution of the article with the strict proviso that no changes or edits are made and the original work is properly cited (including links to both the formal publication through the relevant DOI and the license). See: https://creativecommons.org/licenses/by-nc-nd/4.0/.

\section{References}

1. The Chinese Ministry of Education: Guidance on organizing and managing online teaching in colleges and universities during epidemic prevention and control. (2020-02-04). [2020-08-24]. Available online: http://www.moe.gov.cn/srcsite/A08/s7056/202002/ t20200205_418138.html

2. Li L. The Necessity, Problems, and Development Mechanism of the Virtual Simulation Experiment. Journal of Hubei Open Vocational College 2019;32:151-3.

3. Baker JW. The "classroom flip": Using web course management tools to become the guide on the slide. 11th international conference on college teaching and learning. 2000. Available online: https://classroomflip.com/files/ baker_2000_06_23_classroom_flip_CCCU.pdf

4. Wu H. Research on Model and Molding Experiment Teaching Based on Overturned Classroom. Research and Exploration in Laboratory 2019;38:176-80.

5. Jowsey T, Foster G, Cooper-Ioelu P, et al. Blended learning via distance in pre-registration nursing education: A scoping review. Nurse Educ Pract 2020;44:102775.

6. Sun Z, Sun Y, Wang Q, et al. Exploring the Integration Experimental Courses of Cell Biology: A Proposed Approach for Promoting the Combination of Research and Teaching. Chinese Journal of Cell Biology 2016;38:715-20.

7. Bu WJ, Gong L, Lin AQ. Reform Measures of Improving Teaching Effect of Cell Biology Experiment Course. Modern Agricultural Science and Technology 2017;8:281-2.

8. Lei CQ, Xie ZX, Zhang XY. Preliminary attempt of introducing DNA damage repair experiment into cell biology experimental teaching. Experimental Technology and Management 2020;37:221-3.

9. Cai YF, Chen Y, Shi JS, et al. Exploration of the Designed Experiment of Cell Biology-Drug Resistance Analysis of Tumor Cells. Chinese Journal of Cell Biology 2020;42:673-81.

10. Zhao X, Wang C, Xu XL. Course Construction and Teaching Reform of "Pharmaceutics" Course under the Background of "Double First-class" Construction. Education and Teaching Forum 2020;(24):129-32.

11. Ling JY, Zhang GY, Chen M, et al. The Primary Exploration of the Biotechnological Pharmaceutics Course Construction based on Collaborative Innovation. Higher Education of Sciences 2015;12:101-4.

12. Yu CH, Deng Y. Exploration and practice of biology experiment teaching reform. Laboratory Science 2020;23:136-9.

13. He YX, Li ZY, Liu JH, et al. Evaluation of multiple intelligences theory-based cytobiology experiment teaching. Chemistry of Life 2020;40:965-8.

14. Ministry of Education of the People's Republic of China. The Ministry of Education's implementation opinions 
on the construction of first-class courses. (2019-10-30). Available online: http://www.moe.gov.cn/srcsite/A08/ s7056/201910/t20191031_406269.html

15. Liu Y, Meng W, Meng LJ, et al. Exploration and

Cite this article as: Li P, Li M, Tian L, Xiao J, Xiang G, Ding X, Qin X, Jiang R, Liao J. Exploration and practice of blended teaching of cell biology experiments during the COVID-19 epidemic. Ann Transl Med 2022;10(4):232. doi: 10.21037/atm-22-55
Practice on Innovation Practice Education Mode of Undergraduates. Research and Exploration in Laboratory 2016;35:166-8. 